\title{
Efeito do teor de soro, açúcar e de frutooligossacarídeos sobre a população de bactérias lácticas probióticas em bebidas fermentadas
}

\author{
Karime Giannetti Thamer, Ana Lúcia Barretto Penna* \\ Departamento de Engenharia e Tecnologia de Alimentos, Instituto de Biociências, Letras e Ciências Exatas, \\ Universidade Estadual Paulista, São José do Rio Preto
}

*Correspondência:

A. L. B. Penna

Instituto de Biociências, Letras e Ciências Exatas. Departamento de

Engenharia e Tecnologia de

Alimentos. Rua Cristóvão Colombo,

2265 - Jardim Nazareth. 15054-000 -

São José do Rio Preto - SP.

E-mail: analucia@ibilce.unesp.br.
Nos últimos anos tem havido muito interesse por produtos alimentícios de baixas calorias e probióticos. A incorporação de Lactobacillus acidophilus e Bifidobacterium em bebidas fermentadas pode resultar em um produto lácteo com extraordinário valor terapêutico e eficaz redução calórica. $O$ objetivo deste trabalho foi estudar o efeito do teor de soro, açúcar e de frutooligossacarídeos sobre a população de bactérias lácticas de doze formulações de bebidas fermentadas. Foram determinadas as populações de Streptococcus thermophilus, Lactobacillus delbrueckii subsp. bulgaricus, Bifidobacterium $e$ Lactobacillus acidophilus. As maiores populações de microrganismos probióticos foram observadas nas bebidas com mais baixa acidez e elevado teor de sólidos, além de haver predominância do Streptococcus thermophilus sobre os demais microrganismos. As amostras atenderam a legislação brasileira em vigor, independente das formulações, pela presença de no mínimo $10^{6} \mathrm{UFC} / \mathrm{mL}$ de bactérias lácticas. As bebidas lácteas formuladas podem ser consideradas probióticas pelas contagens elevadas de Bifidobacterium spp. e Lactobacillus acidophilus.
Unitermos

- Alimentos funcionais

- Probióticos

- Bebidas lácteas

\section{INTRODUÇÃO}

Os efeitos benéficos dos leites fermentados tiveram sua base científica no começo do século XX, com o microbiologista russo Eli Metchnikoff, que propôs uma teoria sobre o prolongamento da vida baseado no consumo diário de leites fermentados pelos povos dos Bálcãs (González, 1997). Ele acreditava que a atividade metabólica das bactérias ácido-láticas inibiria as bactérias intestinais do mesmo modo que inibem a putrefação dos alimentos (Adams, Moss, 1997). Suas publicações "The prolongation of life" $\mathrm{e}$ "The bacillus of long life" podem ser consideradas o nascimento dos alimentos probióticos (González, 1997).
Os probióticos são definidos como suplementos microbianos que influenciam positivamente o organismo e aumentam de maneira significativa o valor nutritivo e terapêutico dos alimentos, através do equilíbrio microbiano intestinal e das funções fisiológicas do trato intestinal humano (Goldin, 1998; Shah, 2001). Da mesma forma, alimentos probióticos são definidos como alimentos contendo microrganismos, que possuem efeito benéfico sobre a microflora intestinal e as funções fisiológicas do trato intestinal humano.

Dentre os diversos gêneros que integram este grupo, destacam-se o Bifidobacterium e o Lactobacillus e, em particular, a espécie Lactobacillus acidophilus. Além dos benefícios em termos de nutrição e de saúde que propor- 
cionam, as culturas probióticas podem também contribuir para melhorar o sabor do produto final, possuindo a vantagem de promover acidificação reduzida durante a armazenagem pós-processamento (Gomes, Malcata, 1999).

Até recentemente, o consumo de leites fermentados esteve baseado no iogurte tradicionalmente produzido com fermentos compostos de Lactobacillus delbrueckii ssp. bulgaricus e Streptococcus salivarius ssp. thermophillus. O futuro aponta para o uso de probióticos, associados ou não a esses tradicionais, quer como agentes biotecnológicos, ou seja, que melhoram as características do produto tradicional, por reduzir a pósacidificação do iogurte e leites fermentados, fato evidenciado pela ação de Lactobacillus acidophilus e Bifidobacterium $s p$, quer como agentes terapêuticos, ou seja, microrganismos que promovem efeitos benéficos nos indivíduos que os ingerem (Antunes, 2001).

O consumo de produtos contendo L. acidophilus e $B$. bifidum têm a potencialidade de melhorar os movimentos peristálticos do intestino, aumentando a absorção de nutrientes, prevenindo ou controlando infecções intestinais, bloqueando os receptores dos patógenos, inativando os efeitos das enterotoxinas e favorecendo o desenvolvimento de microrganismos resistentes a patógenos, especialmente contra Escherichia coli (Lee et al., 1999). Além disso, tem a capacidade de melhorar a digestão da lactose em pessoas classificadas como lactose-intolerantes, metabolizar alguns tipos de fármacos, reduzir o nível de colesterol e o risco de câncer de cólon (Gilliland, 1989).

Os Frutooligossacarídeos (FOS) consistem de moléculas de sacarose, nas quais uma ou duas outras unidades de frutose são adicionadas por ligações $\beta$-(2-1) à molécula de frutose da sacarose. O grau de polimerização varia de 2 a 10 unidades. Os derivados de sacarose são encontrados naturalmente em vegetais e plantas como alcachofra, raiz de chicória, dália, dente de leão, alho, cebola, banana e outras. No entanto, a quantidade encontrada nesses alimentos é pequena, exigindo consumo elevado para se obter o efeito funcional esperado. O FOS pode, no entanto, ser extraído desses alimentos e concentrado (Ferreira, 2001).

Entre as propriedades prebióticas estudadas, existe um consenso de que os FOS modificam o habitat intestinal, causando aumento no bolo fecal, normalização da freqüência fecal e efeito prebiótico (aumenta o número de bactérias e/ou atividade do número de bifidobactérias e bactérias ácido-láticas, no intestino humano) (German et al., 1999). Em vista disso, os frutooligossacarídeos têm sido utilizados numa ampla variedade de alimentos como iogurte, leite, queijo, leite de soja, confeitos, cereais em barra e cereais infantis (Pupin, 2002).
Neste contexto, o desenvolvimento de uma bebida láctea fermentada com culturas probióticas e acrescida de prebiótico, torna-se opção interessante para as indústrias de laticínios, assim como atende às expectativas dos consumidores, que buscam alimentos saudáveis, nutritivos e saborosos.

O presente trabalho teve como objetivo estudar o efeito do teor de soro, açúcar e de frutooligossacarídeos sobre a população de bactérias lácteas probióticas em bebidas fermentadas.

\section{MATERIAL E MÉTODOS}

\section{Preparação da cultura láctea}

A cultura mista MY BIO 6 (Ezal-Rhodia) contendo Streptococcus thermophilus, Lactobacillus delbrueckii subsp. bulgaricus, Bifidobacterium e Lactobacillus acidophilus, liofilizada e de uso direto, foi dissolvida assepticamente em um litro de leite desnatado esterilizado e resfriado a $5{ }^{\circ} \mathrm{C}$, para em seguida ser distribuída em frascos esterilizados. Os frascos foram, então, mantidos em congelador, à temperatura de $-18{ }^{\circ} \mathrm{C}$, e na ocasião do uso foram descongelados e a cultura inoculada diretamente na mistura dos ingredientes para a fabricação da bebida láctea.

\section{Preparação das bebidas lácteas}

O leite em pó desnatado (Nestlé) e o soro de leite em pó (Sweetmix) foram misturados, conforme o experimento, totalizando aproximadamente $8 \%$ de sólidos totais, adicionados de açúcar e de frutooligossacarídeos (Nutra Flora P-95), reconstituídos em água e acrescidos de $0,4 \%$ de estabilizante SBB 280 (Danisco Cultor), sob agitação constante e vigorosa. Esta mistura foi aquecida até $85^{\circ} \mathrm{C}$ e mantida por $20 \mathrm{mi}-$ nutos em banho termostatizado. A mistura foi resfriada em banho de água e gelo até atingir $42^{\circ} \mathrm{C}$, para receber a cultura láctica em condições assépticas. O produto foi incubado a $42{ }^{\circ} \mathrm{C}$. O tempo de fermentação da bebida láctea foi calculado a partir do início da inoculação, até obter-se o valor de $\mathrm{pH}$ próximo a 4,7-4,8. Terminada a fermentação, foi feito resfriamento inicial até $20^{\circ} \mathrm{C}$, aproximadamente, e a quebra do coágulo durante 30 segundos por agitação manual, seguida por resfriamento final em banho de água e gelo. A bebida foi embalada em copos plásticos e armazenada em refrigerador à temperatura de $5{ }^{\circ} \mathrm{C}$, aproximadamente.

\section{Caracterização da população de bactérias lácticas}

Foram feitas as diluições decimais seriadas, em que $10 \mathrm{~mL}$ de amostra foram transferidas de forma asséptica para um frasco de Erlenmeyer estéril contendo $90 \mathrm{~mL}$ de 
água destilada estéril. Essa solução foi então homogeneizada e em seguida foram feitas as diluições subseqüentes.

As bebidas lácteas foram avaliadas em duplicata com inoculação por profundidade. A população de Streptococcus thermophilus e Lactobacillus delbrueckii subsp. bulgaricus foram determinadas utilizando-se ágar M 17, seguido de incubação em aerobiose a $37^{\circ} \mathrm{C}$ por 48 horas (IDF,1997) e ágar MRS acidificado, seguido de incubação em anaerobiose a $37^{\circ} \mathrm{C}$ por 72 horas (IDF, 1997), respectivamente. A determinação da população de Bifidobacterium foi feita utilizando-se ágar MRS-IM com glicose e adicionado de soluções de dicloxacilina, cloreto de lítio e cloreto de cisteína, seguida de incubação em anaerobiose a $37^{\circ} \mathrm{C}$ por 72 horas (CHR. Hansen, 1999), e de Lactobacillus acidophilus utilizando-se o ágar MRS-IM com maltose, seguida de incubação em anaerobiose a $37^{\circ} \mathrm{C}$ por 72 horas (IDF, 1999).

\section{Planejamento estatístico dos experimentos e análise dos resultados}

Foram feitas diferentes formulações da bebida láctea, variando-se as concentrações de soro $(45 \%, 50 \%$ e $55 \%)$ em substituição ao leite em pó, de açúcar (6\%, 7\% e 8\%) e de frutooligossacarídeos $(1 \%, 2 \%$ e $3 \%)$. A concentração do estabilizante foi mantida fixa em todas as formulações e todas elas seguiram a mesma seqüência de fabricação.

Os ensaios foram realizados segundo um planejamento experimental do tipo fatorial com três níveis $\left(2^{3}\right) \mathrm{e}$ quatro pontos centrais (Montgomery, 2001). As Tabelas I e II mostram as variáveis independentes e os níveis das variações que foram usados nos doze experimentos.

O ponto central codificado como " 0 " foi selecionado após testes preliminares e segundo dados disponíveis na literatura. Os níveis de variação codificados como -1 e 1 foram escolhidos para cobrir a região experimental conveniente.

Como não se conhecia a relação entre as variáveis independentes e a resposta, uma equação polinomial de segundo grau foi usada para estabelecer um modelo matemático preditivo, segundo Barros Neto, Scarminio e Bruns (1995), cuja equação geral é:

$\mathrm{Y}=\mathrm{b}_{0}+\mathrm{b}_{1} \mathrm{x}_{1}+\mathrm{b}_{2} \mathrm{x}_{2}+\mathrm{b}_{3} \mathrm{x}_{3}+\mathrm{b}_{12} \mathrm{x}_{1} \mathrm{x}_{2}+\mathrm{b}_{13} \mathrm{x}_{1} \mathrm{x}_{3}+\mathrm{b}_{23} \mathrm{x}_{2} \mathrm{x}_{3}+$
$\mathrm{b}_{123} \mathrm{x}_{1} \mathrm{x}_{2} \mathrm{x}_{3}+\mathrm{e}$ em que: "Y" é a função resposta genérica, "X" são as variáveis codificadas, obtidas a partir das variáveis originais, "b" são os coeficientes estimados pela técnica de mínimos quadrados e "e" é o resíduo, medindo o erro experimental.

Foi feita a análise de variância (ANOVA) dos resulta- dos das amostras e a comparação entre médias através do teste de Tukey, utilizando-se o programa ESTAT, desenvolvido por Banzatto, Kronka (1995). Para as análises foi considerado um nível de significância de $5 \%(\mathrm{p}<0,05)$.

TABELA I - Planejamento experimental contendo as variáveis e níveis usados no estudo

\begin{tabular}{ccccc}
\hline Variáveis Originais & & \multicolumn{3}{c}{ Níveis } \\
\cline { 3 - 5 } & & $\mathbf{- 1}$ & $\mathbf{0}$ & $+\mathbf{+ 1}$ \\
\hline Soro & $\mathrm{S} \mathrm{( \% )}$ & 45,0 & 50,0 & 55,0 \\
Açúcar & $\mathrm{A} \mathrm{( \% )}$ & 6,0 & 7,0 & 8,0 \\
Frutooligossacarídeos & FOS (\%) & 1,0 & 2,0 & 3,0 \\
\hline
\end{tabular}

TABELA II - Matriz de ensaios para o projeto fatorial fracionado com as variáveis nas unidades codificadas e originais

\begin{tabular}{ccccccc}
\hline Experimentos & $\mathbf{X}_{\mathbf{1}}$ & $\mathbf{X}_{\mathbf{2}}$ & $\mathbf{X}_{\mathbf{3}}$ & $\begin{array}{c}\mathbf{S} \\
(\mathbf{\%})\end{array}$ & $\begin{array}{c}\mathbf{A} \\
(\mathbf{\%})\end{array}$ & $\begin{array}{c}\text { FOS } \\
(\mathbf{\%})\end{array}$ \\
\hline 1 & $-1,00$ & $-1,00$ & $-1,00$ & 45,0 & 6,0 & 1,0 \\
2 & 1,00 & $-1,00$ & $-1,00$ & 55,0 & 6,0 & 1,0 \\
3 & $-1,00$ & 1,00 & $-1,00$ & 45,0 & 8,0 & 1,0 \\
4 & 1,00 & 1,00 & $-1,00$ & 55,0 & 8,0 & 1,0 \\
5 & $-1,00$ & $-1,00$ & 1,00 & 45,0 & 6,0 & 3,0 \\
6 & 1,00 & $-1,00$ & 1,00 & 55,0 & 6,0 & 3,0 \\
7 & $-1,00$ & 1,00 & 1,00 & 45,0 & 8,0 & 3,0 \\
8 & 1,00 & 1,00 & 1,00 & 55,0 & 8,0 & 3,0 \\
9 & 0,00 & 0,00 & 0,00 & 50,0 & 7,0 & 2,0 \\
10 & 0,00 & 0,00 & 0,00 & 50,0 & 7,0 & 2,0 \\
11 & 0,00 & 0,00 & 0,00 & 50,0 & 7,0 & 2,0 \\
12 & 0,00 & 0,00 & 0,00 & 50,0 & 7,0 & 2,0 \\
\hline
\end{tabular}

$\mathrm{S}=$ teor de soro; $\mathrm{A}=$ teor de açúcar; $\mathrm{FOS}=$ teor de frutooligossacarídeos.

\section{RESULTADOS E DISCUSSÃO}

Os resultados das análises microbiológicas estão apresentados na Tabela III. A caracterização físico-química do leite, do soro e das bebidas lácteas foi efetuada por Thamer e Penna (2004).

A contagem dos microrganismos probióticos Bifidobacterium spp. e Lactobacillus acidophilus (em unidades formadoras de colônias - UFC/mL) variaram de 9,00 x $10^{6}$ a $9,65 \times 10^{12}$ e de $1,15 \times 10^{8}$ a $2,55 \times 10^{12}$, respectivamente. Pode-se verificar que as maiores contagens correspondem ao tratamento 8 , que apresentou o menor teor de acidez e elevado teor de sólidos. No experimento 1, com maior teor de acidez, obtiveram-se as menores contagens. 
As bactérias probióticas (Bifidobacterium e $L$. acidophilus) são mais sensíveis ao abaixamento do valor de $\mathrm{pH}$, apresentando menor viabilidade. A partir deste dado Almeida, Bonassi, Roça (2001) elaboraram uma bebida láctea com valores de $\mathrm{pH}$ entre 5,07 e 5,14 pois algumas espécies de bifidobactéria não se desenvolvem em $\mathrm{pH}$ entre 4,50 e 5,00 .

As contagens de Streptococcus thermophilus e de Lactobacillus delbrueckii subsp. bulgaricus variaram de $8,00 \times 10^{8}$ a $2,42 \times 10^{13}$ e de $1,75 \times 10^{7}$ a 2,76 $\times 10^{11}$, respectivamente. Observou-se predominância de Streptococcus thermophilus em comparação ao Lactobacillus delbrueckii subsp. bulgaricus. O Streptococcus thermophilus e o Lactobacillus delbrueckii subsp. bulgaricus exibem uma relação denominada protocooperação durante a produção da bebida, já que não existe dependência um do outro para a sua sobrevivência. Essas bactérias produzem mais ácido na forma de cultura mista do que ao ser utilizada como culturas isoladas.

Durante a fermentação, o Streptococcus thermophilus cresce rapidamente, utilizando os aminoácidos essenciais produzidos pelo Lactobacillus delbrueckii subsp. bulgaricus. O Streptococcus thermophilus, por sua vez, produz ácido lático e fórmico reduzindo o $\mathrm{pH}$ do meio para um nível ótimo de crescimento do Lactobacillus delbrueckii subsp. bulgaricus. O ácido láctico produzido e pequenas quantidades de ácido fórmico estimulam o crescimento do Lactobacillus delbrueckii subsp. bulgaricus (Hatting, Viljoen, 2001; Moon, Reinbold, 1976; Shah, 2001; Shankar, Davies, 1977; Tamime, Deeth, 1980).
Menores contagens de Lactobacillus delbrueckii subsp. bulgaricus no produto final diminuem a pósacidificação do iogurte durante sua vida-de-prateleira. Isto é importante tanto do ponto de vista sensorial, pois garante ao produto final um sabor suave (Pereira, 2002) como para evitar os efeitos adversos do $\mathrm{pH}$ baixo sobre as bactérias probióticas (Dave, Shah, 1997).

A contagem de probióticos é de fundamental importância para que seja possível a verificação se as bebidas lácteas atendem a legislação em vigor, além da sua influência no sabor e aroma. As diferentes formulações das bebidas podem selecionar de maneira positiva ou negativa $o$ crescimento dos microrganismos.

Segundo Matsubara, (2001), o número de células deve ser muito alto, a legislação da fala em $10^{7}$ UFC do microrganismo por grama do produto, o que é pouco. Melhor seria $10^{9}$, para ter pelo menos cerca de $10^{3}$ a $10^{4}$ UFC alcançando o intestino, sendo que o ideal seria que chegasse a $10^{6}$.

Como a contagem total de probióticos foi de $10^{8}$ a $10^{13} \mathrm{UFC} / \mathrm{mL}$, as bebidas lácteas obtidas apresentaram população de microrganismos suficiente para atuar no intestino humano como probióticos, proporcionando também uma boa qualidade sensorial e de textura. Desta maneira, as doze diferentes formulações de bebidas lácteas fermentadas atenderam aos requisitos descritos na literatura, assim como na legislação brasileira de bebidas lácteas (Brasil, 2000), que preconizam que todos os microrganismos produtores da fermentação láctica devem ser viáveis e estar presentes no produto em quantidades mínimas de $10^{6} \mathrm{UFC} / \mathrm{mL}$.

TABELA III - População de bactérias lácteas presentes nas bebidas lácteas

\begin{tabular}{lccccc}
\hline Experimentos & $\begin{array}{c}\text { Bifidobacterium } \\
(\mathbf{U F C} / \mathbf{m L})\end{array}$ & $\begin{array}{c}\text { Lactobacillus } \\
\text { acidophilus } \\
(\mathbf{U F C} / \mathbf{m L})\end{array}$ & $\begin{array}{c}\text { Streptococcus } \\
\text { thermophilus } \\
(\mathbf{U F C} / \mathbf{m L})\end{array}$ & $\begin{array}{c}\text { Lactobacillus } \\
\text { delbruckii subsp. } \\
\text { bulgaricus }(\mathbf{U F C} / \mathbf{m L})\end{array}$ & $\begin{array}{c}\text { Total de probióticos } \\
(\mathbf{U F C} / \mathbf{m L})\end{array}$ \\
\hline 1 & $9,00 \times 10^{6 \mathrm{~b}}$ & $1,15 \times 10^{8 \mathrm{a}}$ & $8,00 \times 10^{8 \mathrm{~b}}$ & $1,75 \times 10^{7 \mathrm{c}}$ & $1,24 \times 10^{8}$ \\
2 & $1,92 \times 10^{11 \mathrm{~b}}$ & $2,29 \times 10^{11 \mathrm{a}}$ & $1,19 \times 10^{11 \mathrm{~b}}$ & $1,03 \times 10^{9 \mathrm{c}}$ & $4,21 \times 10^{11}$ \\
3 & $7,50 \times 10^{7 \mathrm{~b}}$ & $7,90 \times 10^{8 \mathrm{a}}$ & $3,58 \times 10^{9 \mathrm{~b}}$ & $9,50 \times 10^{7 \mathrm{c}}$ & $8,65 \times 10^{8}$ \\
4 & $7,70 \times 10^{8 \mathrm{~b}}$ & $2,60 \times 10^{8 \mathrm{a}}$ & $1,20 \times 10^{12 \mathrm{~b}}$ & $3,45 \times 10^{8 \mathrm{c}}$ & $1,03 \times 10^{9}$ \\
5 & $2,50 \times 10^{7 \mathrm{~b}}$ & $1,20 \times 10^{11 \mathrm{a}}$ & $1,48 \times 10^{11 \mathrm{~b}}$ & $4,35 \times 10^{8 \mathrm{c}}$ & $1,20 \times 10^{11}$ \\
6 & $1,15 \times 10^{10 \mathrm{~b}}$ & $8,25 \times 10^{10 \mathrm{a}}$ & $7,10 \times 10^{12 \mathrm{~b}}$ & $3,70 \times 10^{8 \mathrm{c}}$ & $9,40 \times 10^{10}$ \\
7 & $8,70 \times 10^{8 \mathrm{~b}}$ & $3,40 \times 10^{8 \mathrm{a}}$ & $6,62 \times 10^{11 \mathrm{~b}}$ & $7,25 \times 10^{8 \mathrm{c}}$ & $1,21 \times 10^{9}$ \\
8 & $9,65 \times 10^{12 \mathrm{a}}$ & $2,55 \times 10^{12 \mathrm{a}}$ & $2,42 \times 10^{13 \mathrm{a}}$ & $9,25 \times 10^{10 \mathrm{~b}}$ & $1,22 \times 10^{13}$ \\
9 & $1,92 \times 10^{11 \mathrm{~b}}$ & $1,50 \times 10^{8 \mathrm{a}}$ & $5,10 \times 10^{12 \mathrm{~b}}$ & $7,50 \times 10^{7 \mathrm{c}}$ & $1,92 \times 10^{11}$ \\
10 & $1,35 \times 10^{11 \mathrm{~b}}$ & $3,75 \times 10^{10 \mathrm{a}}$ & $1,10 \times 10^{13 \mathrm{ab}}$ & $2,76 \times 10^{11 \mathrm{a}}$ & $1,73 \times 10^{11}$ \\
11 & $3,20 \times 10^{8 \mathrm{~b}}$ & $2,50 \times 10^{8 \mathrm{a}}$ & $9,44 \times 10^{11 \mathrm{~b}}$ & $2,10 \times 10^{8 \mathrm{c}}$ & $5,70 \times 10^{8}$ \\
12 & $3,60 \times 10^{10 \mathrm{~b}}$ & $1,31 \times 10^{11 \mathrm{a}}$ & $8,14 \times 10^{11 \mathrm{~b}}$ & $1,26 \times 10^{9 \mathrm{c}}$ & $1,67 \times 10^{11}$ \\
\hline
\end{tabular}

${ }_{a, b, c}$ Médias em uma coluna com diferentes sobrescritos diferem significativamente $(p<0,01)$ 
Menores contagens foram observadas por Silva et al., (2001), que utilizaram para a fermentação da bebida láctea uma cultura mista contendo $S$. thermophilus, $L$. delbrueckii subsp. bulgaricus e L. acidophilus. A análise microbiológica foi feita através da contagem total de microrganismos viáveis, sem a quantificação individual de cada espécie, totalizando $10^{8} \mathrm{UFC} / \mathrm{mL}$.

Foi feita a regressão múltipla com os dados experimentais das populações das bactérias e as variáveis estudadas. O modelo ajustado, representado por uma equação polinomial, não foi significativo estatisticamente para a população de Lactobacillus delbrueckii subsp. bulgaricus. Provavelmente outras variáveis, diferentes das estudadas podem ter influenciado no resultado.

Para o Streptococcus thermophilus, originou-se um modelo ajustado, representado pela equação 2 .

$\mathrm{v}_{1}=4,27 \times 10^{12}+3,98 \times 10^{12} \mathrm{X}_{1}+3,85 \times 10^{12} \mathrm{X}_{3}$

$+3,65 \times 10^{12} \mathrm{X}_{1} \mathrm{X}_{3}$

O resultado do ajuste mostrou dependência das va riáveis $\mathrm{X}_{1}$ (soro) e $\mathrm{X}_{3}$ (FOS), ou seja, aumentando-se a concentração de soro em pó e de frutooligossacarídeo, há aumento na população de Streptococcus thermophilus. O parâmetro estudado apresentou-se independente da variável $X_{2}$ (açúcar), mostrando que a variação de 6 a $8 \%$ de açúcar não foi significativa. A análise de variância do modelo polinomial Streptococcus thermophilus mostrou que $87,83 \%\left(\mathrm{R}^{2}=0,8783\right)$ da variação das respostas pode ser

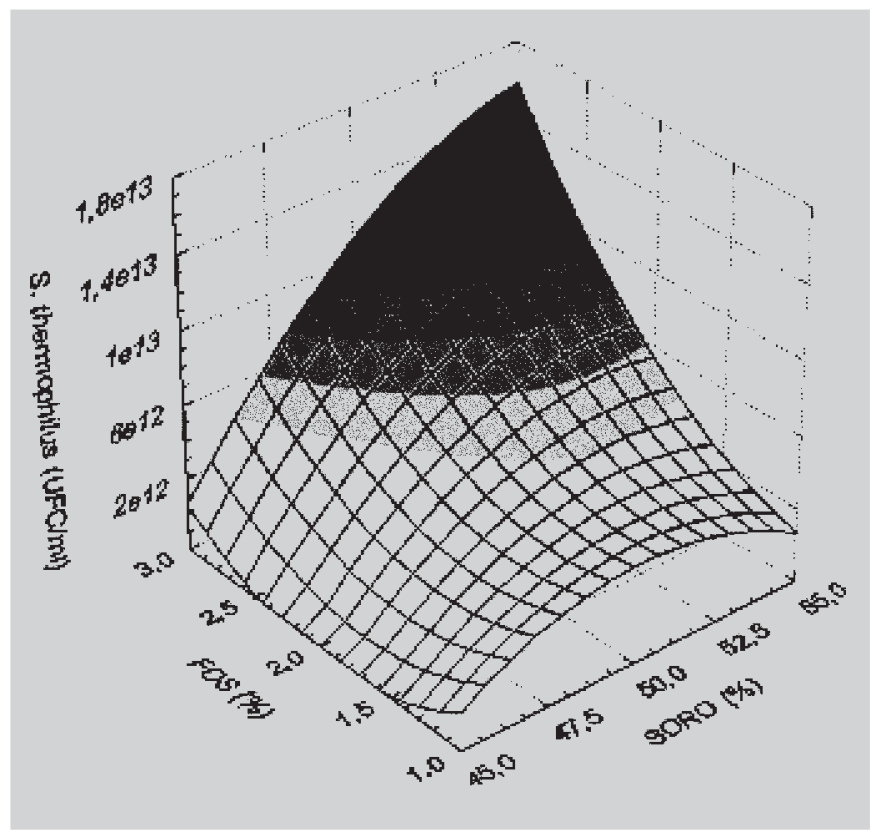

FIGURA 1 - Efeito do teor de soro e frutooligossacarídeos sobre a população de $S$. thermophilus. explicada pela regressão. O nível de significância (p) foi de 0,0946 .

A Tabela IV mostra os valores observados e os valores ajustados para o modelo Streptococcus thermophilus e a Figura 1 mostra a representação tridimensional da superfície de resposta do modelo, com a relação entre o soro em pó e frutooligossacarídeo sobre a população de Streptococcus thermophilus.

Apesar da análise de variância dos resultados encontrados nas contagens de Bifidobacterium mostrar que houve diferença significativa entre os tratamentos (Tabela III), a análise de regressão múltipla para a obtenção de uma equação polinomial completa e os resultados da análise de variância para este modelo, mostraram não ser significativa estatisticamente a regressão obtida. Por isso, a equação não está sendo apresentada. Desta forma não foi possível correlacionar os diferentes níveis das variáveis estudadas com os resultados obtidos.

Este fato mostra que outros fatores, além da concentração de soro em pó, açúcar e frutooligossacarídeos, podem ter influenciado o crescimento dessas bactérias e, por isso, o modelo ajustado não pode ser utilizado para prever a resposta população de Bifidabacterium.

Do mesmo modo que a população de Bifidabacterium, o modelo ajustado para a população de Lactobacillus acidophilus não pode ser utilizado, pois observou-se que muitos valores ajustados resultam em números negativos, o que não faz sentido quando se relaciona à populações de bactérias. Outros fatores, além

TABELA IV - Efeito do teor de soro, açúcar e frutooligossacarídeos sobre a população de Streptococcus thermophilus

\begin{tabular}{lcc}
\hline Experimentos & \multicolumn{2}{c}{$\begin{array}{c}\text { População de Streptococcus } \\
\text { thermophilus }(\mathrm{UFC} / \mathrm{mL})\end{array}$} \\
\cline { 2 - 3 } & Observada & Ajustada pelo modelo \\
\hline 1 & $8,00 \times 10^{8}$ & $9,00 \times 10^{10}$ \\
2 & $1,19 \times 10^{11}$ & $7,50 \times 10^{11}$ \\
3 & $3,58 \times 10^{9}$ & $9,00 \times 10^{10}$ \\
4 & $1,20 \times 10^{12}$ & $7,50 \times 10^{11}$ \\
5 & $1,48 \times 10^{11}$ & $4,90 \times 10^{11}$ \\
6 & $7,10 \times 10^{12}$ & $1,58 \times 10^{13}$ \\
7 & $6,62 \times 10^{11}$ & $4,90 \times 10^{11}$ \\
8 & $2,42 \times 10^{13}$ & $1,58 \times 10^{13}$ \\
9 & $5,10 \times 10^{12}$ & $4,27 \times 10^{12}$ \\
10 & $1,10 \times 10^{13}$ & $4,27 \times 10^{12}$ \\
11 & $9,44 \times 10^{11}$ & $4,27 \times 10^{12}$ \\
12 & $8,14 \times 10^{11}$ & $4,27 \times 10^{12}$ \\
\hline
\end{tabular}


das variáveis estudadas, podem ter influenciado os resultados.

A população de bactérias láticas depende da linhagem utilizada, interação entre as espécies presentes, condições da cultura, composição química do meio (fonte de carboidrato), acidez final, conteúdo de sólidos do leite, disponibilidade de nutrientes, promotores e inibidores de crescimento, concentração de açúcar (pressão osmótica), oxigênio dissolvido (especialmente para a Bifidobacterium), quantidade inoculada, temperatura de incubação, tempo e temperatura de estocagem (Kailasapathy, Rybka, 1997; Hatting, Viljoen, 2001; Shah, 2001).

A adição de bactérias probióticas aos produtos lácteos apresenta uma série de dificuldades, sendo as principais, a pouca palatabilidade e o longo tempo de fermentação. De um modo geral as bactérias bífidas crescem pouco no leite, produzindo pouco ácido resultando em um tempo de fermentação prolongado. Essas bactérias exigem um baixo potencial de oxi-redução (Eh) para iniciar crescimento além de fatores de crescimento. A produção de ácido é crítica e irá definir as características de qualidade e vida de prateleira esperada para o produto. Para isso é importante que um produto lácteo fermentado probiótico, atinja $\mathrm{pH}$ 4,6 no máximo em 24 horas, e as culturas probióticas geralmente não têm essa capacidade. Nesta situação são empregados ajustadores biológicos. As culturas que tem sido empregadas para esse fim são mesofílicas e termofílicas (Streptococcus/Lactobacillus). O emprego de bioajustadores em produtos probióticos tem como finalidade básica resolver problemas de sabor, aroma e textura; aumentar a taxa de crescimento e diminuir o tempo de fermentação; além de garantir o processo fermentativo evitando problemas de contaminação (Ferreira, 2001).

Dos vários estudos de sobrevivência dos microrganismos probióticos realizados por diversos pesquisadores, existe consenso geral de que produtos com acidez elevada (por exemplo o iogurte) conduzem a maior perda de viabilidade do que produtos com baixa acidez (por exemplo iogurte gelado, gelado tradicional e queijo), sendo necessário efetuar uma seleção cuidadosa das estirpes a utilizar. Na tentativa de melhorar a viabilidade em longo prazo das estirpes probióticas, foram executados diversos estudos sobre novas metodologias, que englobam quer a substituição do vetor alimentar quer a proteção de estirpes sensíveis ao ácido por microencapsulação com acetatoftalato de celulose ou com alginato de cálcio (Gomes, Malcata, 1999).

Além da acidez dos produtos e da acidez produzida durante a estocagem refrigerada, o nível de oxigênio nos produtos e sua permeabilidade através das embalagens, a sensibilidade às substâncias produzidas pelas bactérias do iogurte e a falta de nutrientes no leite, são fatores responsáveis pela perda de viabilidade dos microrganismos probióticos (Shah, 2001).

Outro fator importante é que as bifidobactérias necessitam de condições anaeróbias para seu desenvolvimento. Pode ser que durante a fabricação e a estocagem das bebidas lácteas, em copos plásticos de polietileno, esta condição não tenha sido alcançada satisfatoriamente. $\mathrm{O}$ uso de equipamentos de desaeração e de culturas de mistas com $S$. thermophilus na produção de iogurtes favorece o atendimento desta condição. O S. thermophilus tem uma maior habilidade em utilizar o oxigênio. A utilização de embalagens de vidro no lugar das de polietileno e poliestireno também é preferível, já que estas últimas não são barreiras ao oxigênio. A seleção de espécies de bifidobactérias tolerantes ao oxigênio pode ser também uma solução para minimizar o efeito adverso deste gás em bioprodutos fermentados contendo Bifidobacterium e $L$. acidophilus (Arunachalam, 1999).

O crescimento das bifidobactérias pode também ser estimulado pela presença de carboidratos complexos, conhecidos como oligossacrídeos. Certos oligossacarídeos são considerados prebióticos e são usados para maximizar o efeito dos produtos bífidos. Eles servem como fonte de carbono e energia e são referidos como fatores bifidogênicos (Shah, 2001). Dentre eles, a oligofrutose tem sido amplamente utilizada como prebiótico.

Neste trabalho não foi possível observar o estímulo do crescimento das bifidobactérias pelo aumento da concentração de FOS (Tabela III). Castro et al. (2002) avaliaram a influência da oligofrutose, nos níveis de 1 e $3 \%$, no desenvolvimento de culturas lácteas probióticas do iogurte e verificaram que este prebiótico não alterou de forma significativa o desenvolvimento das bifidobactérias. Nesses estudos, a oligofrutose foi adicionada ao leite antes do tratamento térmico. Freitas e Jackix (2002) avaliaram a estabilidade da oligofrutose diante da pasteurização e armazenamento em suco misto de cenoura e laranja através da análise de cromatografia líquida. Os autores observaram que houve uma perda da oligofrutose após a pasteurização do suco, variando de $42-64 \%$ e que este oligossacarídeo foi hidrolisado em frutose devido à pasteurização e o efeito do $\mathrm{pH}$, sendo a estocagem um fator de menor significância. Sendo assim, o efeito prebiótico da oligofrutose pode ter sido prejudicado pelo tratamento térmico prolongado usado na elaboração das bebidas lácteas. 


\section{CONCLUSÕES}

O estudo do efeito das variáveis sobre a população das bactérias láticas mostrou que com o aumento dos teores de soro e FOS, houve aumento na população de Streptococcus thermophilus, entretanto, o teor de açúcar não teve efeito significativo. Além disso, houve predominância de Streptococcus thermophilus sobre os demais microrganismos, com exceção do tratamento 2. Não foi observado aumento na população de bifibobactérias com o aumento da concentração de FOS.

Também se observou que o $\mathrm{pH}$ interferiu na viabilidade da microflora probiótica em leites fermentados. Com o decréscimo do $\mathrm{pH}$ ocorreu uma redução nas contagens de células viáveis de Lactobacillus acidophilus e Bifidobacterium durante a estocagem refrigerada.

Todas as bebidas lácteas atenderam à legislação brasileira em vigor, independente das formulações, e os produtos obtidos podem ser considerados benéficos para a saúde pela presença de no mínimo $10^{6} \mathrm{UFC} / \mathrm{mL}$ de microrganismos probióticos.

\section{ABSTRACT}

\section{Effect of whey, suggar and frutooligosacharides on the probiotic lactic acid bacteria population in fermented beverages}

The demand for low calories and probiotics foods has increased during the last years. The incorporation of Lactobacillus acidophilus and Bifidobacterium in fermented beverages can result in dairy products with excellent therapeutic value and efficient calories reduction. The aim of this research was study the effects of whey, sugar and fructooligosaccharides levels on the lactic acid bacteria population of twelve formulations of fermented beverages. The populations of Streptococcus thermophilus, Lactobacillus delbrueckii subsp. bulgaricus, Bifidobacterium spp. and Lactobacillus acidophilus were carried out. The highest probiotic microorganisms' populations were observed in beverages with lower acidity and higher solids level, besides there was a predominance of Streptococcus thermophilus over the other microorganisms. All samples attended the Brazilian legislation in force, instead of the different formulation, because they presented at least $10^{6}$ colonyforming units per $m L$ of lactic acid bacteria. The produced dairy beverages could be considered probiotics due to the high counts of the Bifidobacterium spp. and Lactobacillus acidophilus.

UNITERMS: Functional foods. Probiotics. Dairy beverages.

\section{AGRADECIMENTOS}

Os autores agradecem à Fundação de Amparo à Pesquisa do Estado de São Paulo (FAPESP), pelo suporte financeiro.

\section{REFERÊNCIAS BIBLIOGRÁFICAS}

ADAMS, M.R.; MOSS, M.O. Microbiologia de los Alimentos. Zaragoza: Acribia, 1997. 464p.

ALMEIDA, K.E.; BONASSI, I.A.; ROÇA, R.O. Características físicas e químicas de bebidas lácteas fermentadas e preparadas com soro de queijo minas frescal. Cien. Tec. Al., Campinas, v. 2, n. 2, p. 187-192, 2001.

ANTUNES, L.A.F. Microrganismos probióticos e alimentos funcionais. Rev. Ind. Laticínios, São Paulo, v. 6, n. 34, p. 30-34, 2001.

ARUNACHALAM, K.D. Role of bifidobacteria in nutrition, medicine and technology. Nutr. Res., v. 19, n. 10, p. 1559$1597,1999$.

BANZATTO, D.A., KRONKA, S.D. Experimentação agrícola. $3^{\circ}$ ed. Jaboticabal: FUNESP, 1995, 247p.

BARROS NETO, B., SCARMINIO, I.S., BRUNS, R.E. Planejamento e otimização de experimentos. Campinas: Ed. da UNICAMP, 1995. 299p.

BRASIL, Ministério da Agricultura e Abastecimento. Regulamento Técnico de Identidade e Qualidade de Bebidas Lácteas. Diário Oficial da União de 08/11/2000, Seção I, p. 22-23.

CASTRO, L.P.; PINHEIRO, M.V.S.; HOFFMANN, F.L.; PENNA, A.L.B.; Influência da oligofrutose no desenvolvimento de culturas lácticas probióticas do iogurte. XVIII Congresso Brasileiro de Ciência e Tecnologia de Alimentos. Anais, p. 2.773-2.776, 2002.

CHR. HANSEN. Method for counting probiotic bactéria. Lactobacillus acidophilus, Lactobacillus casei and Bifidobacteria in milk products made with nu-trish cultures. 1999. 4 p. [Guideline].

DAVE, R.I.; SHAH, N.P. Viability of yoghurt and probiotic bacteria in yoghurts made from commercial starter cultures. Int. Dairy J., n. 7, p. 31-41, 1997. 
FERREIRA, C.L.L.F. Tecnologia para produtos lácteos funcionais: probióticos. In: PORTUGAL, J.A.B., CASTRO, M.C.D., SILVA, P.H.F., SAVINO, A.C., NEVES, B.S., ARCURI, E.F. O Agronegócio do leite e os alimentos lácteos funcionais, Juiz de Fora: EPAMIG - Centro Tecnológico - ILCT, p. 183-203, 2001.

FREITAS, D.D.G.C., JACKIX, M.N.H. Estabilidade de fruto-oligossacarídeos adicionado em suco misto de laranja e cenoura. XVIII Congresso Brasileiro de Ciência e Tecnologia de Alimentos. Anais, p. 1.819-1.823, 2002.

GERMAN, B.; SCHIFFRIN, E.J.; RENIERO, R.; MOLLET, B.; PFEIFER, A.; NEESER, J.R. The development of functional foods: lessons from the gut. Trends Biotechnol., Amsterdam, v. 17, n. 12, p. 492-499, 1999.

GILLILAND, S.E. Acidophilus milk products: a review of potential benefits to consumers. J. Dairy Sci., Champaign v. 72, n. 10, p. 2483-2494, 1989.

GOLDIN, B.R. Health beneficts of probiotics. Br. J. Nutr., London, v. 80, n. 4, p. S 203-207, 1998.

GOMES, A.M.P., MALCATA, F.X. Agentes probióticos em alimentos: aspectos fisiológicos e terapêuticos, e aplicações tecnológicas. Bol. Biotecnol. Al., São Paulo, n. 64, p. 12-22, 1999.

GONZÁLEZ, S. Alimentos lácticos probióticos. In: LERAYER, A.L.S., SALVA, T.J.G., coords. Leites fermentados e bebidas lácteas. Campinas: ITAL, 1997. p. 10.1-10.6.

HATTING, A.L., VILJOEN, B.C. Yogurt as probiotic carrier food. Int. Dairy J., Barking, v. 11, n. 1-2, p. 1-17, 2001.

IDF. INTERNATIONAL DAIRY FEDERATION STANDARD 117B: 1997. Enumeration of characteristic microorganisms. IDF/ISO Standard, 1997. 5p.

IDF. INTERNATIONAL DAIRY FEDERATION. Detection and enumeration of Lactobacillus acidophilus. Bull. Int. Dairy Fed., Brussels, n. 306, p. 23-33, 1999.

KAILASAPATHY, K.; RYBKA, S. L. acidophilus and Bifidobacterium $\mathrm{sp}$ - their therapeutic potential and survival in yogurt. Austr. J. Dairy Technol., Highett, v. 52, n. 1, p. 28-35, 1997.
LEE, Y.K., NOMOTO, K., SALMINEN, S., GORBACH, S.L. Handbook of probiotics. New York: John Wiley \& Sons, Inc., 1999. 211p.

MATSUBARA, S. Alimentos Funcionais: uma tendência que abre perspectivas aos laticínios. Revista Indústria de Laticínios, São Paulo, n. 34, p. 10-18, 2001.

MONTGOMERY, D.C. Design and Analysis of Experiments. New York: John Wiley \& Sons, Inc., 2001, 684 p.

MOON, N.J.; REINBOLD, G.W. Commensalism and competition in mixed cultures of Lactobacillus bulgaricus and Streptococcus thermophilus. J. Milk Food Technol., Ames, v. 39, n. 5, p. 337-341, 1976.

PEREIRA, M.A.G. Efeito do teor de lactose e do tipo de cultura no processo de acidificação e pós-acidificação de iogurte. Campinas: FEA/UNICAMP, 2002. [Dissertação de Mestrado].

PUPIN, A.M. Probióticos, prebióticos e simbióticos: aplicações em alimentos funcionais. Seminário Novas Alternativas de Mercado, Campinas: ITAL, p. 133-145, 2002.

SHAH, N.P. Functional foods from probiotics and prebiotics. Food Technol., Chicago, v. 55, n. 11, p. 46-52, 2001.

SHANKAR, P.A.; DAVIES, F.L. Associative bacterial growth in yogurt starters, initial observation on stimulatory factors. J. Soc. Dairy Technol., Wembley, v. 30, n. 1, p. 31-32, 1997.

SILVA, M.R.; FERREIRA, C.L.L.F.; COSTA, N.M.B.; MAGALHÃES, J. Elaboração e avaliação de uma bebida láctea fermentada à base de soro de leite fortificada com ferro. Rev. Inst. Lat. Cândido Tostes, Juiz de Fora, v. 56, p. 7-14, 2001.

TAMIME, A.Y.; DEETH, H.C. Yogurt: technology and biochemistry. J. Food Prot., Ames, v. 43, n. 12, p. 939971, 1980.

THAMER, K.G.; PENNA, A.L.B. Caracterização de bebidas lácteas probióticas e acrescidas de prebiótico. $12^{\circ}$ Simpósio Internacional de Iniciação Científica da USP, "Campus" Luiz de Queiroz (ESALQ), Piracicaba, 2004.

Recebido para publicação em 27 de janeiro de 2005. Aceito para publicação em 05 de agosto de 2005. 